\title{
Assessment of milk yield and composition, early reproductive performance, and herd removal in multiparous dairy cattle based on the week of diagnosis of hyperketonemia in early lactation
}

\author{
Z. Rodriguez, ${ }^{1} \oplus$ E. Shepley, ${ }^{1} \odot$ M. I. Endres,${ }^{2} \odot$ G. Cramer, ${ }^{1} \odot$ and L. S. Caixeta ${ }^{1 *} \odot$ \\ ${ }^{1}$ Department of Veterinary Population Medicine, University of Minnesota, St. Paul 55108 \\ ${ }^{2}$ Department of Animal Science, University of Minnesota, St. Paul 55108
}

\begin{abstract}
The purpose of this retrospective cohort study was to evaluate the effects of the timing of hyperketonemia (HYK) diagnosis during early lactation on milk yield and composition, reproductive performance, and herd removal. Plasma $\beta$-hydroxybutyrate (BHB) was measured twice a week during the first 2 wk of lactation in 362 multiparous Holstein cows for the diagnosis of HYK. In each week, cows were diagnosed as HYK positive $(\mathrm{HYK}+)$ if the plasma $\mathrm{BHB}$ concentrations were $\geq 1.2 \mathrm{mmol} / \mathrm{L}$ in at least one of the tests for the week evaluated. Milk-related outcomes (first 10 monthly milk tests) included milk yield, milk fat and protein content, milk urea nitrogen (MUN), and linear score of somatic cell count. Other performance outcomes of interest included risk of pregnancy within $150 \mathrm{~d}$ in milk (DIM) and herd removal (i.e., culling or death) within 300 DIM. Statistical models were built separately for cows diagnosed with HYK during the first week of lactation (wk1) and for cows diagnosed during the second week of lactation (wk2). All models for wk2 were adjusted by HYK diagnosed in wk1, along with other potential confounder variables. The association between HYK in each week and milk-related outcomes was assessed using generalized estimated equation models that accounted for repeated measures. Time to pregnancy and time to herd removal were analyzed using Cox's proportional hazard regression models. Seventy-eight cows (21.5\%) tested positive for HYK during wk1, 60 cows $(16.6 \%)$ in wk2, and 29 cows $(8.0 \%)$ in both weeks. Hyperketonemia during wk1 was associated with a milk yield reduction of $3.7 \mathrm{~kg}$ [95\% confidence interval (CI): -6.67 to -0.76$]$ per cow per day throughout the lactation. Meanwhile, we did not observe evidence of an association between HYK diagnosed during wk2 and milk yield. During the first 2 monthly milk tests, cows
\end{abstract}

Received June 7, 2021.

Accepted January 10, 2022.

*Corresponding author: lcaixeta@umn.edu diagnosed as $\mathrm{HYK}+$ in wk1 had greater fat $(0.42 \%$; 95\% CI: 0.16 to 0.67 ) and MUN (0.75 mg/dL; $95 \%$ CI: 0.26 to 1.24$)$ content in milk than HYK-negative $(\mathrm{HYK}-)$ cows. We did not detect any evidence of an association between HYK diagnosed in wk2 and these outcomes. The HYK+ cows in wk1 had a 30\% [hazard ratio $(\mathrm{HR})=0.70 ; 95 \% \mathrm{CI}: 0.48$ to 1.01$]$ lower risk of pregnancy within $150 \mathrm{DIM}$ and 2.48 times $(95 \% \mathrm{CI}$ : 1.63 to 2.89 ) higher risk of herd removal within 300 DIM than HYK - cows. Conversely, no evidence of association was observed between HYK+ cows in wk2 and risk of pregnancy by 150 DIM $(\mathrm{HR}=0.98 ; 95 \%$ CI: 0.64 to 1.51 ) or removal from the herd within 300 DIM (HR $=0.91 ; 95 \%$ CI: 0.52 to 1.60$)$. Our findings indicate that HYK diagnosed during wk1 of lactation is associated with negative performance in terms of milk yield, reproduction, and herd removal. No evidence of association was found for the same outcomes when HYK was diagnosed in wk2. Our results suggest the need to consider the timing when HYK is diagnosed when investigating its association with performance outcomes.

Key words: beta-hydroxybutyrate, hyperketonemia, dairy cow, transition period

\section{INTRODUCTION}

During the transition from late gestation to early lactation, cows experience important physiological and metabolic changes (Bauman and Currie, 1980). The capacity of dairy cows to adapt to their new physiological state will determine their health and productivity after calving (Herdt, 2000). As part of the metabolic adaptation, dairy cows mobilize body reserves - specifically fatty acids from adipose tissue, which ultimately become ketone bodies - to be used as alternative sources of energy (Herdt, 2000). An excessive circulation of ketone bodies, also known as hyperketonemia (HYK), is associated with compromised health, productivity, and reproductive performance (Ospina et al., 2010; Suthar et al., 2013; Raboisson et al., 2014). Thus, a 
high prevalence of HYK diagnosed during the first $2 \mathrm{wk}$ after calving is traditionally considered an indicator of problems in the transition period.

Screening protocols to diagnose HYK typically involve the testing of cows during the first 2 wk of lactation because of the elevated prevalence of HYK reported during this period (van der Drift et al., 2012; Suthar et al., 2013; Santschi et al., 2016).

Previous studies have suggested that an increase in disease events and a decrease in milk yield and reproductive efficiency are observed with lower BHB concentration thresholds in the first week (wk1) compared with the second (wk2; Walsh et al., 2007; Duffield et al., 2009). The etiology, severity, and metabolic adaptations that cause the energy deficit that leads to the mobilization of fatty acids may differ between HYK diagnosed in different weeks in the early postpartum period. Although elevated BHB concentrations early after calving are often associated with other diseases, elevated BHB concentrations later in the lactation may be related to high demands of glucose for milk production that surpasses the capacity of the liver for gluconeogenesis (Holtenius and Holtenius, 1996; Herdt, 2000; Bobe et al., 2004). Hence, the timing of HYK diagnosis may result in different effects on health and production, as previously described (Duffield et al., 2009), and may need to be considered when investigating the association of HYK and performance.

To our knowledge, there is limited information on the effects of HYK, diagnosed at different weeks postpartum and using a single threshold $(1.2 \mathrm{mmol} / \mathrm{L})$, on cow performance throughout her lactation. Therefore, our objective was to evaluate the association of HYK in the first and second weeks of lactation with milk yield and composition, reproductive performance, and herd removal throughout a single entire lactation. We hypothesized that HYK diagnosed in the first week postpartum negatively affects milk yield and composition, reproductive performance, and herd removal, whereas HYK diagnosed during the second week of lactation would have no effect on performance.

\section{METHODS}

\section{Study Population}

All study activities were approved by the University of Minnesota Institutional Animal Care and Use Committee (St. Paul, MN), protocol number 1806-36016A.

The current retrospective cohort study was conducted on a commercial dairy farm in Minnesota. The herd was selected for its convenience due to herd size $(1,200$ milking cows), reliable data records, use of computerized data recording and management software (Dairy-
Plan C21, GEA Farm Technologies), and lack of BHB testing and HYK treatment protocols. Holstein dairy cows were housed in freestalls with recycled manuresolid bedding. Lactating cows were milked 3 times a day, and the farm participated in the Dairy Herd Improvement program.

\section{Study Design, Data Collection, and Farm Management}

The data used in the analyses were originally collected for another study evaluating the accuracy of an algorithm for the prediction of HYK postpartum using prepartum blood metabolites. The research team visited the herd for sample collection from February to October 2019. In the original study, a total of 362 multiparous cows were enrolled $3 \mathrm{wk}$ before their expected calving date. Blood samples used for BHB measurement in the present study were collected twice a week, 3 to $4 \mathrm{~d}$ apart, between 1 and $14 \mathrm{~d}$ postpartum (d $3 \pm$ 2, $6 \pm 2,9 \pm 2$, and $12 \pm 2$ ). All samples were collected from the coccygeal vessels using a 20 -gauge, $2.54-\mathrm{cm}$ blood collection needle, and vacuum tubes containing lithium-heparin (Vacutainer, Becton Dickinson). All blood collection took place immediately after the morning milking when cows returned to their pen to freshly delivered feed. Blood samples were immediately placed in a cooler after collection and transported on ice to the laboratory. Within $3 \mathrm{~h}$ of collection, all samples were centrifuged at $2,000 \times g$ for $15 \mathrm{~min}$ at $4^{\circ} \mathrm{C}$ for plasma separation and kept frozen at $-80^{\circ} \mathrm{C}$ for later analysis. Samples were thawed at the end of the study for the measurement of BHB. Samples were measured in duplicates with a small-scale chemistry analyzer (CatachemWell-T, Catachem Inc.) using a commercial enzymatic assay kit (assay range: $0.2-2.5 \mathrm{mmol} / \mathrm{L}$; CataChem Inc.) previously used by others (Stokol and Nydam, 2006; Leno et al., 2017; Pralle et al., 2021). The intra- and inter-coefficients of variation for the BHB assay were $3.5 \%$ and $8.0 \%$, respectively. Hyperketonemia was defined as plasma BHB $\geq 1.2 \mathrm{mmol} / \mathrm{L}$ (Duffield, 2000; McArt et al., 2013). Thus, cows with at least one BHB measurement $\geq 1.2 \mathrm{mmol} / \mathrm{L}$ during wk1 were considered as hyperketonemia positive $(\mathbf{H Y K}+)$ in wk1, otherwise as negative $(\mathbf{H Y K}-)$. Similarly, all cows tested in wk1 were also tested in wk2 regardless of their HYK status, unless they were culled or died, and the same BHB threshold of $1.2 \mathrm{mmol} / \mathrm{L}$ was applied. Diagnostic results were not shared with farm personnel, and no cows were treated for HYK during the study.

Information on milk yield and composition was obtained from 10 monthly test records for each individual cow. Farm personnel recorded calving ease, culling and death, and disease events using standardized definitions. 
Calving ease was recorded using a 4 -point scale $(1=$ no assistance provided; 2 = light assistance by one person without the use of mechanical traction; $3=$ mechanical extraction of the calf with an obstetric calf-puller; and $4=$ severe dystocia with surgery or fetotomy needed; Schuenemann et al., 2011). Disease events were diagnosed and recorded by farm personnel. Before the start of the study, standard disease definitions (LeBlanc et al., 2002) were discussed with farm personnel. Briefly, clinical mastitis was defined as a change in the appearance of the milk or udder, indicative of infection. The placenta was considered retained if present (i.e., hanging out of the vulva) for $24 \mathrm{~h}$ after calving. Milk fever was defined as stage II hypocalcemic parturient paresis. Metritis was defined as purulent or red-brownish fetid uterine discharge with temperature $\geq 39.5^{\circ} \mathrm{C}\left(103.5^{\circ} \mathrm{F}\right)$. Displaced abomasum was a veterinary diagnosis of a right- or left-side abomasal displacement. Disease events were categorized as either presence or absence of at least one of the diseases recorded.

Cows received their first insemination by timed AI following a Double-Ovsynch program with a voluntary waiting period of 65 DIM. Subsequent inseminations happened following estrus detection, and cows that did not demonstrate estrus behaviors before pregnancy diagnosis examination were submitted to a Resynch program. Pregnancy was diagnosed by the herd veterinarian at $32 \pm 3 \mathrm{~d}$ after breeding and reconfirmed at $60 \pm$ $3 \mathrm{~d}$ after breeding. All information was extracted from the farm computer records. In addition, the research team assessed cows' BCS at enrolment on a 5-point scale with 0.25-point increments (Ferguson et al., 1994) and recorded the season of calving (spring $=$ FebruaryApril; summer $=$ May-July; fall = August-October $)$.

\section{Statistical Analyses and Model-Building Strategies}

All statistical analyses were performed using $\mathrm{R}$ 3.4.4 software (R Studio Inc.), and the individual cow was the unit of interest. Results are discussed in the context of precision of the estimate using the confidence interval rather than statistical significance whenever possible (Poole, 2001). From the original sample size $(\mathrm{n}=362), 20$ cows were excluded, resulting in analyses of 342 cows. The sample size was originally developed for a purpose other than the current study. According to the post hoc estimation, the data set allows us to observe a difference equal to or greater than $18.5 \%$ for pregnancy to 150 DIM, $18.1 \%$ of herd removal to 300 DIM, and $3.6 \mathrm{~kg} / \mathrm{d}$ of milk yield, with a significance level of $5 \%$ and a power of $80 \%$ (Epitools, http:// epitools.ausvet.com.au).

Descriptive statistics were generated by HYK status and by week of diagnosis using a chi-squared test or
Fisher's exact test for categorical variables and ANOVA for continuous variables. The exposure variables of interest were HYK status in wk1 and in wk2. Thus, all models were built for wk1 and wk2 separately. The dependent variables of interest were (1) milk-related outcomes [monthly milk yield, milk fat and protein content, MUN, and linear SCC (LSCC)]; (2) pregnancy by 150 DIM; and (3) herd removal (i.e., culling or death) by 300 DIM.

To determine the variations of milk-related outcomes throughout the lactation, we built generalized estimated equation models. We selected this model because subsequent monthly measurements throughout the lactation are highly correlated. The generalized estimated equation model incorporates the dependence among variables from the same cow (i.e., correlation within subject) and provides robust variance estimates of the contrast coefficients. After evaluating several covariance structures, the autoregressive covariance structure was selected based on Akaike's information criterion. All models included linear and quadratic interaction terms with time, and, as such, monthly patterns of milk-related outcomes are reported using graphs and as averages throughout the lactation.

Time to pregnancy and time to herd removal were analyzed using multivariable Cox's proportional hazards regression models. Individual time at risk for the pregnancy model was calculated as the number of days from the end of the voluntary waiting period (65 DIM) to the date of pregnancy diagnosis or censoring (i.e., death, loss of follow-up, or censoring at 150 DIM). For the herd removal model, individual time at risk was calculated as the number of days from calving date to date of culling, death, or censoring (i.e., loss to followup or administrative censoring at 300 DIM). To test the proportional hazards assumption, the scaled Schoenfeld residuals were plotted against the survival time for the final models. In addition to the multivariable Cox models, adjusted survival curves were built to present a visual representation of the outcomes over time and to calculate the median time to event.

Independent variables offered into the wk1 and wk2 multivariable models to test for confounding included parity, BCS at 3 wk before expected calving date, calving ease, and season at calving. Although disease events could occur before or after HYK diagnosis, we included only diseases events before d 7 postpartum as a potential confounder. Disease events after $7 \mathrm{~d}$ postpartum were not included as a confounder because they could be a consequence of HYK. From the previous lactation, variables considered for adjustment included 305-d mature equivalent, days in lactation, days carried calf, and length of the dry period. Variables were considered confounders and remained in the model if they 
had a $10 \%$ change in the estimate criterion (Greenland and Pearce, 2015) under a manual backward stepwise elimination procedure. Once confounding effects were determined, biologically plausible 2-way interactions were investigated for the remaining covariates. The HYK status in wk1 was forced in all wk2 models as a confounder. This is a limitation of our data analysis, as we cannot separate whether HYK in wk2 is a result of HYK in wk2 postpartum alone or an effect of persistent HYK from wk1. Lastly, the interaction between HYK in wk1 and wk2 was not included in any of the final analyses because of the low number of animals in the study, hindering our ability to compare all 4 groups of cows (i.e., HYK + only in wk1, HYK+ only in wk2, HYK + in both weeks, and HYK - in both weeks).

\section{RESULTS}

\section{Descriptive Statistics}

In total, 362 multiparous Holstein dairy cows were enrolled during the study period. Eleven cows were excluded from the milk-related statistical analyses due to a complete lack of monthly tests results (3 cows were HYK + , and 8 were HYK-). Twenty cows were excluded from the reproductive analyses due to culling before the end of the voluntary waiting period ( 5 cows were $\mathrm{HYK}+$, and 15 were HYK-). Characteristics of the cows enrolled in the study, presented by HYK status and week of testing, are shown in Table 1 . The prevalence of HYK was $21.5 \%(78 / 362)$ in wk1 and $16.6 \%$ $(60 / 362)$ in wk2. In addition, $8.0 \%(29 / 362)$ of the cows were diagnosed with HYK in both weeks. In the univariate analyses presented in Table 1 , the variables parity, previous days dry (length of the previous dry period), previous 305-d mature equivalent, and disease events were statistically associated with HYK in wk1. Previous lactation, gestation length, and disease events were statistically associated with HYK in wk2.

\section{Milk Yield and Composition}

Among cows tested in wk1 for HYK, the HYK+ cows had reduced milk volume throughout the lactation compared with HYK - cows (Figure 1A). Specifically, the wk1 HYK+ cows produced an average of $3.7 \mathrm{~kg} / \mathrm{d}$ (95\% CI: -6.67 to -0.76 ) less milk compared with wk1 HYK - cows (Table 2). The production difference equates to a production loss of $1,128.5 \mathrm{~kg}$ per cow - an $8.0 \%$ decline over $305 \mathrm{~d}$ of lactation. Conversely, among cows tested during wk2 of lactation, the HYK+ cows had a $1.5 \mathrm{~kg} / \mathrm{d}(95 \% \mathrm{CI}:-4.04$ to 1.05$)$ decrease in milk production compared with HYK- cows (Table
2, Figure 1B). Figures $1 \mathrm{C}$ and $1 \mathrm{D}$ show the milk fat content throughout the lactation according to the HYK status diagnosed in wk1 and wk2, respectively. Cows diagnosed as HYK+ in wk1 had a higher milk fat content $(0.42 \%, 95 \%$ CI: 0.16 to 0.67$)$ than those diagnosed as HYK- during the first 2 monthly milk tests. This resulted in a difference in milk fat production of 8.6 $\mathrm{kg} / \mathrm{cow}$ in the first $60 \mathrm{~d}$ of lactation. Nevertheless, the difference in fat content among cows diagnosed with and without HYK in wk1 disappeared as the lactation progressed, with no evidence of a difference between groups when considering the entire lactation. Cows diagnosed as HYK+ during wk2 had greater milk fat content compared with HYK - cows between the third and fifth months of lactation $(0.33 \%, 95 \%$ CI: 0.12 to 0.58). This effect resulted in a difference in milk fat production of $10.1 \mathrm{~kg} / \mathrm{cow}$ between the third and fifth months of lactation. In addition, the average milk fat content during the entire lactation was greater for wk2 HYK + cows compared with HYK - cows $(0.29 \%, 95 \%$ CI: 0.08 to 0.51$)$. This difference in the milk fat content is equivalent to $74.0 \mathrm{~g}$ of milk fat per cow per day (22.58 kg of milk fat per cow in $305 \mathrm{~d}$ of lactation).

Milk protein content did not show evidence of a difference between HYK+ and HYK - cows in either wk1 or wk2 (Figure 1E and 1F, Table 2). The concentration of MUN was higher among cows diagnosed as HYK+ in wk1 compared with HYK - only during the first 2 monthly milk tests $(0.75 \mathrm{mg} / \mathrm{dL}, 95 \%$ CI: 0.26 to 1.24 ; Figure 1G). The average concentration of MUN during the entire lactation did not show evidence of a difference by HYK status or week of diagnosis (Table 2). Cows diagnosed as HYK+ in wk2 had higher LSCC than HYK - cows throughout the lactation $(0.82,95 \%$ CI: 0.25 to 1.39 ). Among cows diagnosed in wk1, HYK+ cows had LSCC 0.49 greater (95\% CI: -0.06 to 1.04 ) than HYK - cows (Table 2).

\section{Reproductive Performance}

The Cox proportional hazard model for reproductive performance within 150 DIM shows that HYK+ cows diagnosed during wk1 had $30 \%$ lower risk of pregnancy than HYK - cows (hazard ratio $=0.70,95 \%$ CI: 0.48 to 1.01). Cows diagnosed with HYK during wk2 had a risk of pregnancy similar to that of HYK - cows (hazard ratio $=0.98,95 \%$ CI: 0.64 to 1.51 ), after adjusting by HYK in the previous week. The median days to pregnancy for HYK + and HYK - cows in wk1 were 116 and 97 DIM, respectively. For cows diagnosed with HYK in wk2, the median days to pregnancy for HYK+ and HYK - cows were 95 and 99 DIM, respectively (Figure 2 ). The proportion of pregnant cows at 150 DIM was 
$48.7 \%$ for wk1 HYK + compared with $63.3 \%$ for wk1 HYK - cows, and $58.3 \%$ for wk2 HYK + compared with $63.0 \%$ for HYK - cows.

\section{Herd Removal}

Cows diagnosed with HYK in wk1 had 2.48 times higher risk of being removed from the herd within 300 DIM than wk1 HYK - cows (95\% CI: 1.63 to 2.89; Figure 3A). However, among HYK+ and HYK - cows diagnosed in wk2, after adjusting for HYK status in wk1, a similar risk of herd removal by 300 DIM (hazard ratio $=0.91,95 \%$ CI: 0.52 to 1.60 ; Figure 3B) was observed. At 300 DIM, the proportions of animals removed from the herd were $55.1 \%$ and $29.5 \%$ for wk1 HYK+ and
HYK - cows, respectively, and $50.0 \%$ and $30.9 \%$ for wk2 HYK + and HYK - cows.

\section{DISCUSSION}

The present study was conducted to explore the consequences of HYK diagnosed at wk1 and wk2 postpartum on the performance of multiparous dairy cows. In our study, we observed that the prevalence of HYK was similar in the first 2 wk postpartum. A similar prevalence in both weeks is in agreement with previous reports showing that the highest prevalence of HYK occurs during the first 2 wk of lactation (van der Drift et al., 2012; Suthar et al., 2013; Santschi et al., 2016).

Table 1. Descriptive characteristics of 362 multiparous dairy cows enrolled in a retrospective study to assess the effect of hyperketonemia diagnosed in the first or second week after calving on milk yield and milk composition, early reproductive performance, and herd removal ${ }^{1}$

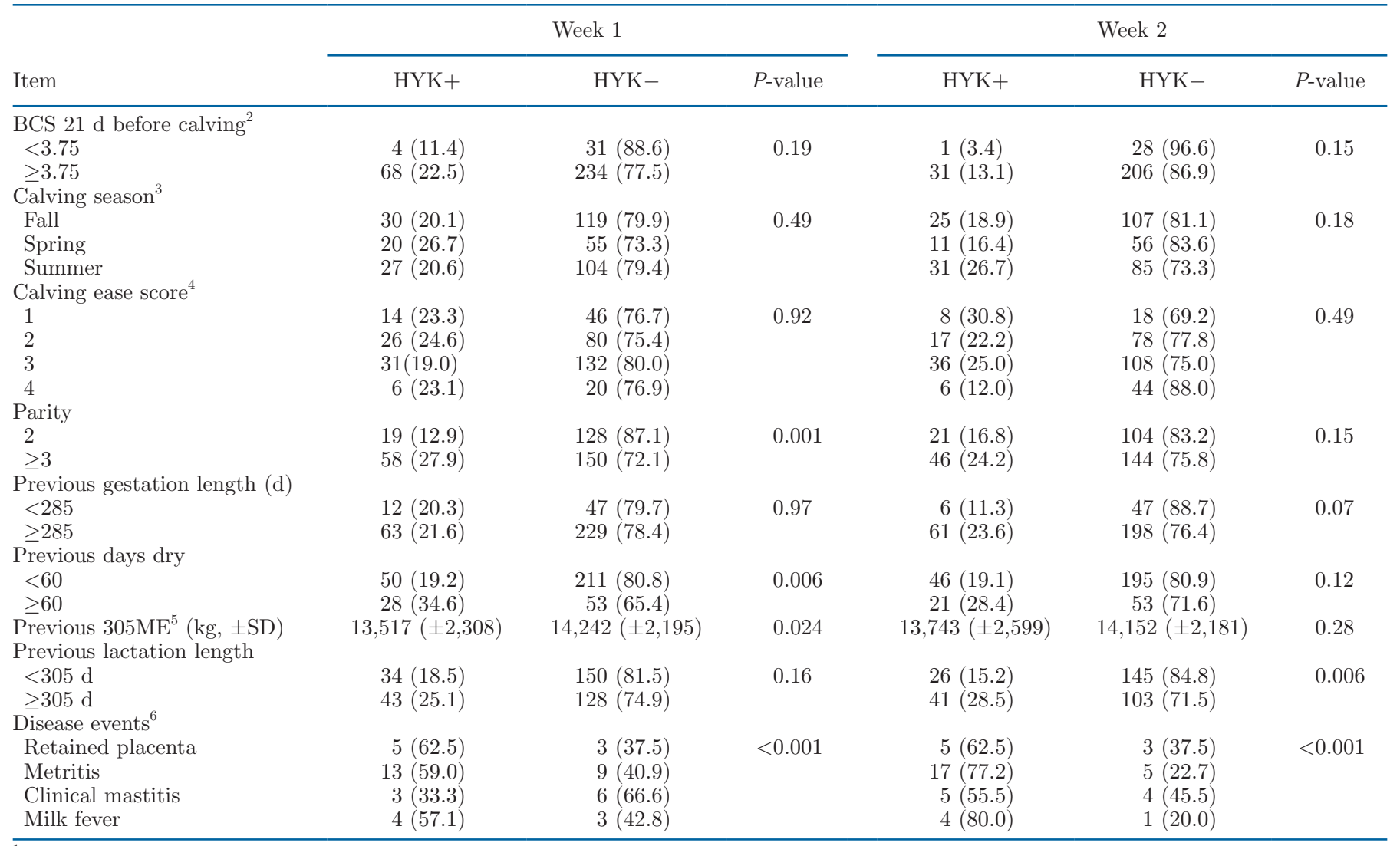

${ }^{1} \mathrm{HYK}+=$ Cows were classified as hyperketonemia positive if they had at least one test above the cut-point (BHB $\left.\geq 1.2 \mathrm{mmol} / \mathrm{L}\right)$ and otherwise were classified as hyperketonemia negative (HYK-; BHB $<1.2 \mathrm{mmol} / \mathrm{L})$. Values shown are number and percentage (in parentheses) of cows per group. P-values from chi-squared, Fisher's, or ANOVA analyses.

${ }^{2} \mathrm{BCS}$ measured $21 \mathrm{~d}$ before the expected calving date.

${ }^{3}$ Seasons: spring $=$ February-April; summer $=$ May-July; fall = August-October.

${ }^{4}$ Calving ease score (assistance provided at birth) based on a 4 -point scale $(1=$ no assistance provided; $2=$ light assistance by one person without the use of mechanical traction; $3=$ mechanical extraction of the calf with an obstetric calf-puller; $4=$ severe dystocia, surgery or fetotomy needed).

${ }^{5} 305 \mathrm{ME}=305$-d mature equivalent milk yield.

${ }^{6}$ Disease events within $7 \mathrm{~d}$ after calving. 

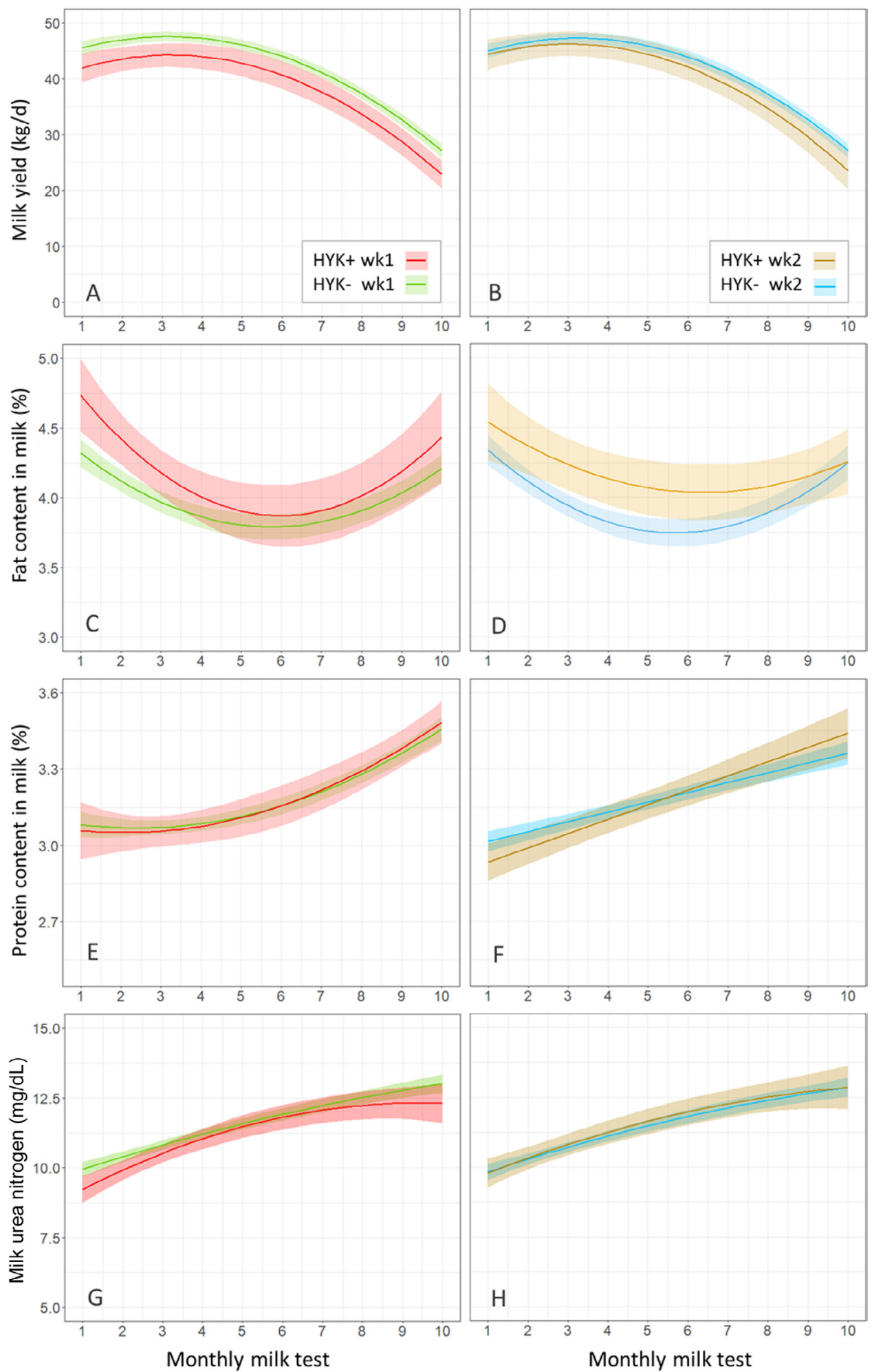

Figure 1. Estimated marginal means and $95 \%$ CI by monthly test for daily milk volume $(\mathrm{kg})$ according to the diagnosis of hyperketonemia (HYK) in week 1 (wk1, A) and week 2 (wk2, B) after calving; daily fat content in milk (\%) in wk1 (C) and wk2 (D); daily protein content in milk (\%) in wk1 (E) and wk2 (F); daily MUN $(\mathrm{mg} / \mathrm{dL})$ in wk1 $(\mathrm{G})$ and wk2 $(\mathrm{H})$. Red and yellow lines represent HYK positive (HYK+) in wk1 and HYK negative (HYK-) in wk1, respectively. Orange and blue lines represent HYK + in wk2 and HYK- in wk2, respectively. Number of cows diagnosed in wk1 (A, C, E, G): HYK $+=75, \mathrm{HYK}-=276$. Number of cows diagnosed in wk2 (B, D, F, H): HYK $+=58, \mathrm{HYK}-=293$.

The final models related to milk yield and composition included linear and quadratic interaction terms with time, and were adjusted by parity and BCS at $21 \mathrm{~d}$ before calving. HYK in wk2 models also included HYK in the previous week. 

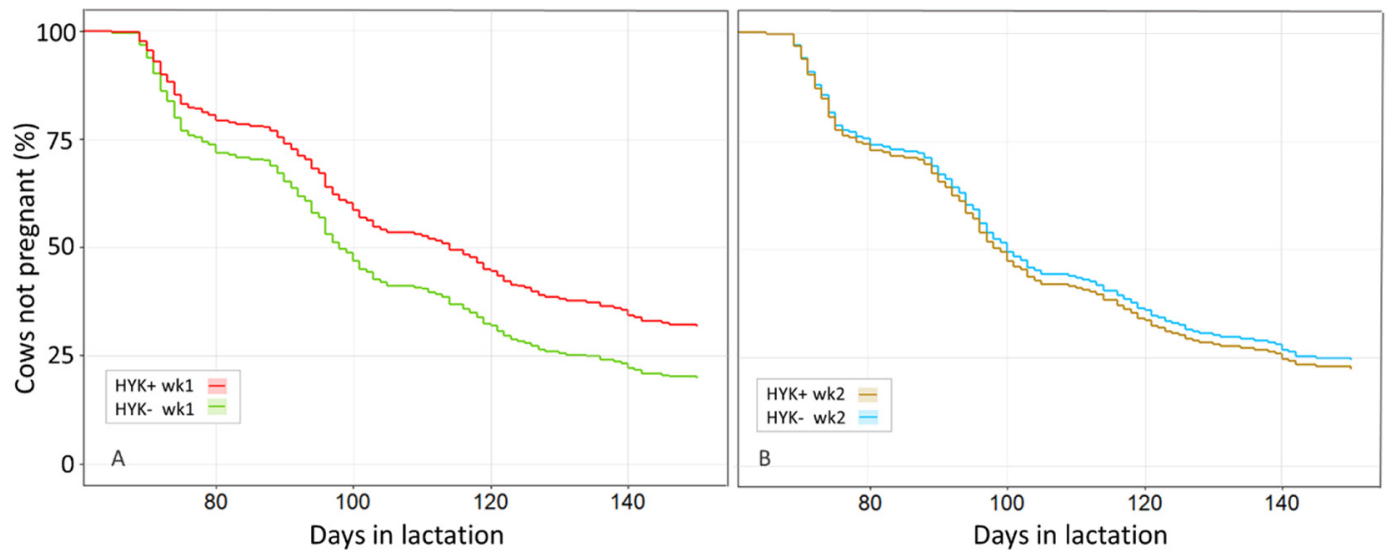

Figure 2. Cox proportional hazard curves for time to pregnancy up to 150 DIM, according to the diagnosis of hyperketonemia (HYK) and moment of diagnosis. (A) Diagnosis of HYK in the first week of lactation (wk1). Red line represents HYK-positive cows (HYK+) wk1 (n = 78), and yellow line represents HYK-negative cows $(H Y K-)$ wk1 $(n=264)$. (B) Diagnosis of HYK in the second week of lactation (wk2). Orange line represents HYK+ cows wk2 $(\mathrm{n}=54)$, and blue line represents HYK - cows wk2 $(\mathrm{n}=288)$. Median days to pregnancy for HYK+ and HYKcows diagnosed in wk1 were 116 and 97 DIM, respectively. Median days to pregnancy for HYK+ and HYK- cows diagnosed in wk2 were 95 and 99 DIM, respectively. The final models related to reproductive performance for wk1 and wk2 analyses included adjustment by parity and days dry before calving, with wk2 analyses also including wk1 HYK status.

Our results showed that wk1 HYK+ cows produced substantially less milk throughout lactation than wk1 HYK - cows, whereas wk2 HYK + cows (including a model adjustment by wk1 HYK + and HYK - cows) had a biologically relevant, but not statistically different, reduction $(-1.5 \mathrm{~kg} / \mathrm{d})$ in milk yield throughout the lactation compared with wk2 HYK - cows. Previous studies evaluating the association between HYK during the first 2 wk of lactation, independent of the time of diagnosis, and milk production in early lacta- tion have shown conflicting results. Some studies have reported milk losses among HYK+ cows ranging from 1.2 to $2.3 \mathrm{~kg} / \mathrm{d}$ at the first milk test compared with HYK - cows (Chapinal et al., 2012; McArt et al., 2012; Santschi et al., 2016). Others have shown an increase in milk yield from 1.2 to $2.4 \mathrm{~kg} / \mathrm{d}$ during the same period when comparing HYK+ and HYK - cows (Vanholder et al., 2015; Rathbun et al., 2017; Ruoff et al., 2017). An explanation for these contradictory results may be the time of HYK diagnosis. For instance, among the

Table 2. Estimated marginal means for milk yield and milk components based on 10 monthly milk tests for 362 multiparous cows enrolled in a retrospective study to assess the effect of hyperketonemia diagnosed in the first or second week after calving ${ }^{1}$

\begin{tabular}{|c|c|c|c|c|}
\hline Item $^{2}$ & HYK+ & HYK- & $\begin{array}{l}\text { Mean diff. per day } \\
(95 \% \mathrm{CI})^{3}\end{array}$ & $P$-value \\
\hline \multicolumn{5}{|l|}{ Wk1 diagnosis ${ }^{3}$} \\
\hline Milk (kg) & $42.4(1.6)$ & $46.1(0.8)$ & $-3.7(-6.67,-0.83)$ & 0.013 \\
\hline Fat $(\%)$ & $3.9(0.1)$ & $3.9(0.0)$ & $0.02(-0.21,0.17)$ & 0.83 \\
\hline Protein (\%) & $3.1(0.0)$ & $3.1(0.0)$ & $0.00(-0.08,0.07)$ & 0.87 \\
\hline MUN (mg/dL) & $11.5(0.2)$ & $11.7(0.1)$ & $-0.18(-0.63,0.26)$ & 0.41 \\
\hline $\mathrm{LSCC}^{4}$ & $3.8(0.3)$ & $3.3(0.1)$ & $0.49(-0.06,1.04)$ & 0.083 \\
\hline \multicolumn{5}{|l|}{ Wk2 diagnosis } \\
\hline Milk (kg) & $43.7(1.4)$ & $45.2(1.0)$ & $-1.5(-4.04,1.05)$ & 0.24 \\
\hline Fat $(\%)$ & $4.1(0.1)$ & $3.8(0.1)$ & $0.29(0.08,0.51)$ & 0.007 \\
\hline Protein (\%) & $3.1(0.0)$ & $3.1(0.0)$ & $0.00(-0.06,0.05)$ & 0.88 \\
\hline MUN (mg/dL) & $11.6(0.2)$ & $11.5(0.1)$ & $0.12(-0.37,0.63)$ & 0.62 \\
\hline LSCC & $4.2(0.3)$ & $3.6(0.2)$ & $0.82(0.25,1.39)$ & 0.004 \\
\hline
\end{tabular}

${ }^{1} \mathrm{HYK}+=$ Cows were classified as hyperketonemia positive if they had at least one test above the cut-point $(\mathrm{BHB} \geq 1.2 \mathrm{mmol} / \mathrm{L})$ and otherwise were classified as hyperketonemia negative $(\mathrm{HYK}-; \mathrm{BHB}<1.2 \mathrm{mmol} / \mathrm{L})$. SE shown in parentheses.

${ }^{2}$ Final models related to milk yield and composition included linear and quadratic interaction terms with time, and were adjusted by parity and BCS at $21 \mathrm{~d}$ before calving. HYK in wk-2 models also included HYK in the previous week.

${ }^{3}$ Mean difference of HYK+ compared with HYK - cows (reference), with $95 \%$ confidence interval.

${ }^{4} \mathrm{LSCC}=$ linear score of milk SCC. 

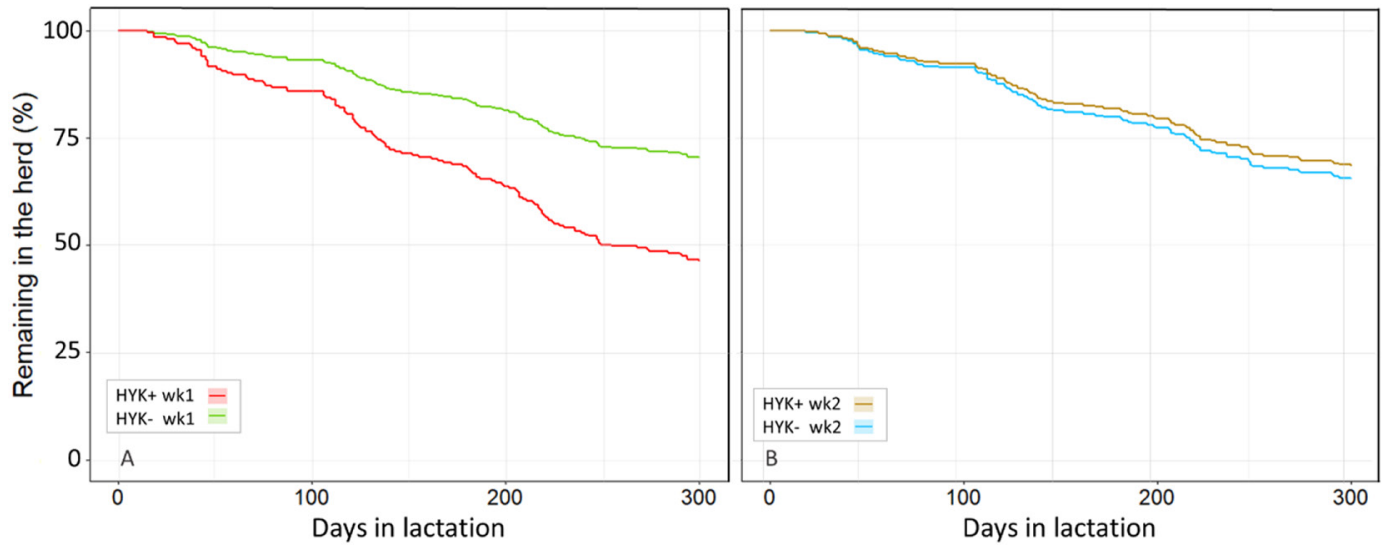

Figure 3. Cox proportional hazard curves for time to herd removal up to 300 DIM, according to diagnosis of hyperketonemia (HYK) and moment of diagnosis. (A) Diagnosis of HYK in the first week of lactation (wk1). Red line represents HYK-positive cows $(\mathrm{HYK}+)$ wk1 $(\mathrm{n}=78)$, and yellow line represents HYK-negative cows $(\mathrm{HYK}-)$ wk1 $(\mathrm{n}=264)$. (B) Diagnosis of HYK in the second week of lactation (wk2). Orange line represents HYK + cows wk2 $(\mathrm{n}=60)$, and blue line represents HYK - cows wk2 $(\mathrm{n}=285)$. The final models for herd removal included adjustment by parity and disease events as confounders when analyzing wk1 HYK and parity, disease events, previous lactation milk yield, and HYK in wk1 as confounders when analyzing wk2 HYK.

aforementioned studies, those that observed a negative association reported a higher HYK prevalence in wk1, whereas studies that observed a positive association reported a higher HYK prevalence in wk2. This is further supported by a study by Duffield et al. (2009), which reported that cows diagnosed with HYK in the first week postpartum produced $1.22 \mathrm{~kg}$ less milk at the first monthly test than HYK- cows. This suggests that cows with HYK diagnosed in wk1 have a higher risk of milk yield reduction. However, it is worth mentioning that we compared HYK status within each week, but we did not directly compare the effect of HYK diagnosed in wk1 against HYK diagnosed in wk2. Thus, we cannot declare a statistically different effect of HYK between weeks but only point to numerical differences. Furthermore, wk1 HYK status was included in the wk2 statistical models, making it difficult to confirm that the results are driven entirely by wk2 HYK status. One reason wk1 HYK+ cows have lower milk yield than wk1 HYK - cows may be a poor adaptation of wk1 HYK + cows to the new lactating physiological state compared with HYK- cows. Previous studies have reported higher levels of insulin resistance, oxidative stress, and triacylglycerides accumulated in the liver, and low hepatic gluconeogenic capacity in cows with HYK in early lactation (Emery et al., 1992; Xu et al., 2015; Youssef and El-Ashker, 2017). Therefore, despite the new physiological state being a challenging period for all cows, those diagnosed with HYK in wk1 are likely the ones afflicted by poor metabolic adaptations.

Differences in milk composition throughout the lactation were less evident than differences in milk yield. Milk fat content increased in cows with a HYK diagnosis in wk1, but only during the first 2 monthly tests. As previous reports suggest, variations in milk fat content are generally minor, ranging from $0.10 \%$ to $0.66 \%$ (van der Drift et al., 2012; Vanholder et al., 2015). Similar to our findings, Santschi et al. (2016) observed an increase in milk fat content on the first monthly test of $0.36 \%$ and $0.18 \%$ in cows diagnosed with HYK in wk1 and wk2, respectively. The effect of HYK in milk fat content is likely due to the exacerbated fat mobilization experienced by cows with HYK soon after calving. Although differences in milk fat yield content between HYK - and HYK + cows in wk1 did not persist past the first 2 mo of lactation, occurrence of HYK in wk2 was associated with an increase in fat content throughout the entire lactation. A more active mammary gland with more de novo fatty acids and medium-chain fatty acid synthesis may be behind the increase in fat content in the entire lactation among cows diagnosed with HYK in wk2 (Mann et al., 2016). A milk fatty acid profile could clarify this difference in milk fat content in the short and long terms. Another milk component that is also related to oxidative stress and liver apoptosis damage is MUN (Song et al., 2016). It has been previously reported that HYK+ cows produce between $4.6 \%$ to $16.6 \%$ less MUN compared with HYK - cows (Santschi et al., 2016). In our study, we observed that the reduction in MUN (8.9\%) in the first 2 mo of lactation for cows diagnosed with HYK in wk1 was within that range. The decrease in MUN is indicative of inefficient use of nitrogen and low protein biosynthesis by the liver, likely as a result of reduced 
feed intake, oxidative stress, and liver dysfunction - all factors associated with the occurrence of HYK (Song et al., 2016).

The estimate of the association between HYK and pregnancy by 150 DIM suggested a negative association between HYK and reproductive performance among cows diagnosed in wk1 and no association among cows diagnosed in wk2. Similarly, in a previous study, Walsh et al. (2007) reported a reduced probability of pregnancy after the first service, occurring with a BHB concentration of $1.0 \mathrm{mmol} / \mathrm{L}$ in wk1 and $1.4 \mathrm{mmol} / \mathrm{L}$ in wk2. Reproductive efficiency is highly related to energy availability and can be affected by an energy deficit in early lactation. (Herdt, 2000; Butler, 2003). According to Butler and Smith (1989), the duration and severity of this energy deficit result in poor reproductive performance. Therefore, a possible explanation for the reproductive performance impairment observed in cows with HYK in wk1 is that it was caused by a poor transition followed by an elevated energy deficit after calving. Conversely, cows with HYK in wk2, which also includes cows with HYK in wk1, may have experienced a better adaptive response to the metabolic challenge of the transition period, thus overcoming the increased energy required for early milk yield without causing a delayed commencement of ovulation, resulting in unimpaired reproductive performance (Dawuda et al., 2002; Butler, 2003). Results from a recent study corroborate this hypothesis. According to Rodriguez et al. (2022), HYK was associated with impaired reproductive performance in cows with low milk yield in the first week postpartum - used as a proxy for unsuccessful adaptation to the new physiological state - whereas high-producing cows had reproductive results similar to cows not diagnosed with HYK.

Herd removal was significantly higher in wk1 HYK+ cows compared with wk1 HYK - cows, an association that was not observed in wk2. However, the difference in the proportion of wk2 HYK + and HYK - cows removed from the herd by 300 DIM was remarkable ( $50.0 \%$ vs. $31.2 \%$, respectively). The lack of association between HYK status and herd removal in wk2 is likely explained by the fact that approximately $50 \%$ of wk2 HYK + cows were also HYK+ in wk1. Thus, once the model was adjusted by wk1 HYK status, the association between HYK status in the wk2 and herd removal was not significant. The association observed between HYK in wk1 and herd removal can be mediated through multiple diseases. For instance, we observed a larger LSCC in cows with HYK in wk1, which was reflected in the proportions of clinical mastitis cases observed in the first 60 DIM (5.6\% in HYK+ and 4.7\% in HYK-), indicating a potential reason for culling of HYK+ cows. Although in the published literature the effect of HYK on intramammary infections is controversial, a meta-analysis reported that the odds of developing subclinical mastitis (i.e., SCC $>200,000$ cells $/ \mathrm{mL}$ ) was $1.42(95 \%$ CI: 1.26 to 1.60$)$ times higher for HYK+ cows than for HYK - cows (Raboisson et al., 2014). In addition, milk fat and protein yield and reproductive performance - all outcomes in this study-may have acted as mediators between HYK and herd removal. Multiple studies have found associations between poor milk yield or reproductive performance and the probability of herd removal (Smith et al., 2000; Alvåsen et al., 2014; Shahid et al., 2015). However, from our study, we cannot be certain that milk yield and reproductive performance mediated the effect of HYK in herd removal.

Our findings should be interpreted while considering some model assumptions and limitations of the current study. The effects observed for HYK in both weeks with respect to the evaluated outcomes are also driven by the assumptions used to build the statistical models. For example, the association between HYK in wk1 and the evaluated outcomes include a potential effect caused by HYK in wk2, which makes HYK in wk2 a mediator that we are not interested in adjusting for. The HYK in wk1, however, was included as a confounder rather than a mediator to the models investigating the association between HYK in wk2 and the outcomes of interest. We acknowledge that adjusting the wk2 models based on HYK in wk1 might not be sufficient to address this limitation, and we are unable to assess whether the wk2 HYK + results are a consequence of HYK in wk2 alone or if it is the result of persistent HYK from wk1, since about half of our wk2 HYK+ cows were also HYK+ in the first week postpartum. This limitation needs to be considered when interpreting our results.

Although reporting the effect of HYK in cows diagnosed as positive in both weeks is not the scope of this study, nor is it possible given the reduced number of cows with such a status, the performance of such animals is of relevance. A synergistic effect is biologically plausible, whereby the cumulative effect of HYK during the first $2 \mathrm{wk}$ of lactation is worse than the sum of the effects of HYK in each week alone. This scenario deserves further consideration, given that, if a synergistic effect exists, HYK+ cows in the first week would benefit from a further diagnostic test in the following week.

Further studies using a larger sample size could be beneficial for declaring the significance of less strong associations or observing estimates with better precision than in our study, while maintaining the same power and significance level. Our findings should not be extrapolated to other BHB thresholds, as the results are expected to change, which would require specific evalu- 
ation. Finally, the incorporation of measurements such as fat infiltration in the liver and insulin and glucose concentrations should be considered in future studies to help elucidate the etiology of HYK at different time points in early lactation.

\section{CONCLUSIONS}

Our study findings indicate that, when using the same threshold $(1.2 \mathrm{mmol} / \mathrm{L})$ to diagnose HYK in the first 2 wk of lactation, HYK diagnosed during wk1 of lactation is associated with negative performance in terms of milk yield, reproduction, and herd removal throughout the lactation. No associations, however, were observed when HYK was diagnosed during wk2 of lactation. Although the models built to investigate the association between wk2 HYK+ and performance outcomes were adjusted for wk1 HYK, approximately half of the wk2 HYK+ cows were also HYK+ in the first week postpartum. Thus, our results for HYK diagnosed during wk2 postpartum should be interpreted with caution. Despite these limitations, our results suggest that the week postpartum when HYK is diagnosed should be considered, as its association with performance outcomes might be different. Further research is warranted to understand the underlying causes of the effects of HYK at different time points and to investigate the use of a different threshold when diagnosing HYK at a different time in early lactation.

\section{ACKNOWLEDGMENTS}

This research was funded partially by Ajinomoto Co. Inc. (Tokyo, Japan). The first author was partially funded by a MnDrive Research Fellowship (University of Minnesota, St. Paul). The funding institutions had no involvement in the study design, data collection, analysis, and interpretation, manuscript preparation, or the decision to submit for publication. The authors also thank the owner of the participating dairy for allowing us access to their facilities and the veterinary medicine students Pedro P. C. Ferro, Nilon L. Moraes, Matheus G.S. Santos, Acir M. Antunes (University of Minnesota, St. Paul), who helped with sample collection. Zelmar Rodriguez was involved in study conceptualization, data collection, management, and analysis, and manuscript preparation; Elise Shepley was involved in manuscript editing and reviewing; Marcia Endres was involved in funding acquisition and manuscript editing and reviewing; Gerard Cramer was involved in manuscript editing and reviewing, and supervision; Luciano Caixeta was involved in study conceptualization, funding acquisition, manuscript editing and reviewing, and supervision. The authors have not stated any conflicts of interest.

\section{REFERENCES}

Alvåsen, K., M. Jansson Mörk, I. R. Dohoo, C. H. Sandgren, P. T. Thomsen, and U. Emanuelson. 2014. Risk factors associated with on-farm mortality in Swedish dairy cows. Prev. Vet. Med. 117:110120. https://doi.org/10.1016/j.prevetmed.2014.08.011.

Bauman, D. E., and W. Bruce Currie. 1980. Partitioning of nutrients during pregnancy and lactation: A review of mechanisms involving homeostasis and homeorhesis. J. Dairy Sci. 63:1514-1529. https:// doi.org/10.3168/jds.S0022-0302(80)83111-0.

Bobe, G., J. W. Young, and D. C. Beitz. 2004. Invited review: Pathology, etiology, prevention, and treatment of fatty liver in dairy cows. J. Dairy Sci. 87:3105-3124. https://doi.org/10.3168/jds .S0022-0302(04)73446-3.

Butler, W. R. 2003. Energy balance relationships with follicular development, ovulation and fertility in postpartum dairy cows. Livest. Prod. Sci. 83:211-218. https://doi.org/10.1016/S0301 $-6226(03) 00112-\mathrm{X}$.

Butler, W. R., and R. D. Smith. 1989. Interrelationships between energy balance and postpartum reproductive function in dairy cattle. J. Dairy Sci. 72:767-783. https://doi.org/10.3168/jds.S0022 $-0302(89) 79169-4$

Chapinal, N., M. E. Carson, S. J. LeBlanc, K. E. Leslie, S. Godden, M. Capel, J. E. P. Santos, M. W. Overton, and T. F. Duffield. 2012. The association of serum metabolites in the transition period with milk production and early-lactation reproductive performance. J. Dairy Sci. 95:1301-1309. https://doi.org/10.3168/jds.2011-4724.

Dawuda, P. M., J. R. Scaife, J. S. M. Hutchinson, and K. D. Sinclair. 2002. Mechanisms linking under-nutrition and ovarian function in beef heifers. Anim. Reprod. Sci. 74:11-26. https://doi.org/10 .1016/S0378-4320(02)00166-5.

Duffield, T. 2000. Subclinical ketosis in lactating dairy cattle. Vet. Clin. North Am. Food Anim. Pract. 16:231-253. https://doi.org/ 10.1016/S0749-0720(15)30103-1.

Duffield, T. F., K. D. Lissemore, B. W. McBride, and K. E. Leslie. 2009. Impact of hyperketonemia in early lactation dairy cows on health and production. J. Dairy Sci. 92:571-580. https://doi.org/ $10.3168 /$ jds.2008-1507.

Emery, R. S., J. S. Liesman, and T. H. Herdt. 1992. Metabolism of long chain fatty acids by ruminant liver. J. Nutr. 122(Suppl. 3):832-837. https://doi.org/10.1093/jn/122.suppl_3.832.

Ferguson, J. D., D. T. Galligan, and N. Thomsen. 1994. Principal descriptors of body condition score in Holstein cows. J. Dairy Sci. 77:2695-2703. https://doi.org/10.3168/jds.S0022-0302(94)77212 $-\mathrm{X}$.

Greenland, S., and N. Pearce. 2015. Statistical foundations for modelbased adjustments. Annu. Rev. Public Health 36:89-108. https:// doi.org/10.1146/annurev-publhealth-031914-122559.

Herdt, T. H. 2000. Ruminant adaptation to negative energy balance: Influences on the etiology of ketosis and fatty liver. Vet. Clin. North Am. Food Anim. Pract. 16:215-230. https://doi.org/10 .1016/S0749-0720(15)30102-X.

Holtenius, P., and K. Holtenius. 1996. New aspects of ketone bodies in energy metabolism of dairy cows: A review. J. Vet. Med. A 43:579-587. https://doi.org/10.1111/j.1439-0442.1996.tb00491.x.

LeBlanc, S. J., T. F. Duffield, K. E. Leslie, K. G. Bateman, J. TenHag, J. S. Walton, and W. H. Johnson. 2002. The effect of prepartum injection of vitamin $\mathrm{E}$ on health in transition dairy cows. J. Dairy Sci. 85:1416-1426. https://doi.org/10.3168/jds.S0022 -0302(02)74209-4.

Leno, B. M., C. M. Ryan, T. Stokol, D. Kirk, K. P. Zanzalari, J. D. Chapman, and T. R. Overton. 2017. Effects of prepartum dietary cation-anion difference on aspects of peripartum mineral and energy metabolism and performance of multiparous Holstein cows. J. Dairy Sci. 100:4604-4622. https://doi.org/10.3168/jds.2016-12221.

Mann, S., D. V. Nydam, A. L. Lock, T. R. Overton, and J. A. A. McArt. 2016. Short communication: Association of milk fatty ac- 
ids with early lactation hyperketonemia and elevated concentration of nonesterified fatty acids. J. Dairy Sci. 99:5851-5857. https: //doi.org/10.3168/jds.2016-10920.

McArt, J. A. A., D. V. Nydam, and G. R. Oetzel. 2012. Epidemiology of subclinical ketosis in early lactation dairy cattle. J. Dairy Sci. 95:5056-5066. https://doi.org/10.3168/jds.2012-5443.

McArt, J. A. A., D. V. Nydam, G. R. Oetzel, T. R. Overton, and P. A. Ospina. 2013. Elevated non-esterified fatty acids and $\beta$-hydroxybutyrate and their association with transition dairy cow performance. Vet. J. 198:560-570. https://doi.org/10.1016/j.tvjl 2013.08.011.

Ospina, P. A., D. V. Nydam, T. Stokol, and T. R. Overton. 2010. Associations of elevated nonesterified fatty acids and $\beta$-hydroxybutyrate concentrations with early lactation reproductive performance and milk production in transition dairy cattle in the northeastern United States. J. Dairy Sci. 93:1596-1603. https://doi.org/10.3168/jds .2009-2852.

Poole, C. 2001. Low $P$-values or narrow confidence intervals: Which are more durable? Epidemiology 12:291-294. https://doi.org/10 .1097/00001648-200105000-00005.

Pralle, R. S., S. J. Erb, H. T. Holdorf, and H. M. White. 2021. Greater liver PNPLA3 protein abundance in vivo and in vitro supports lower triglyceride accumulation in dairy cows. Sci. Rep. 11:2839. https://doi.org/10.1038/s41598-021-82233-0.

Raboisson, D., M. Mounié, and E. Maigné. 2014. Diseases, reproductive performance, and changes in milk production associated with subclinical ketosis in dairy cows: A meta-analysis and review. J. Dairy Sci. 97:7547-7563. https://doi.org/10.3168/jds.2014-8237.

Rathbun, F. M., R. S. Pralle, S. J. Bertics, L. E. Armentano, K. Cho, C. Do, K. A. Weigel, and H. M. White. 2017. Relationships between body condition score change, prior mid-lactation phenotypic residual feed intake, and hyperketonemia onset in transition dairy cows. J. Dairy Sci. 100:3685-3696. https://doi.org/10.3168/ jds.2016-12085.

Rodriguez, Z., E. Wynands, E. Shepley, L. H. Baumgard, G. Cramer, and L. S. Caixeta. 2022. Exploring the role of milk yield in the first week of lactation on the association between hyperketonemia and reproductive performance in dairy cattle. JDS Commun. 3:7-12. https://doi.org/10.3168/jdsc.2021-0129.

Ruoff, J., S. Borchardt, and W. Heuwieser. 2017. Short communication: Associations between blood glucose concentration, onset of hyperketonemia, and milk production in early lactation dairy cows. J. Dairy Sci. 100:5462-5467. https://doi.org/10.3168/jds .2016-12237.

Santschi, D. E., R. Lacroix, J. Durocher, M. Duplessis, R. K. Moore, and D. M. Lefebvre. 2016. Prevalence of elevated milk $\beta$-hydroxybutyrate concentrations in Holstein cows measured by Fourier-transform infrared analysis in Dairy Herd Improvement milk samples and association with milk yield and components. J. Dairy Sci. 99:9263-9270. https://doi.org/10.3168/jds.2016-11128.

Schuenemann, G. M., I. Nieto, S. Bas, K. N. Galvão, and J. Workman. 2011. Assessment of calving progress and reference times for obstetric intervention during dystocia in Holstein dairy cows. J. Dairy Sci. 94:5494-5501. https://doi.org/10.3168/jds.2011-4436.
Shahid, M. Q., J. K. Reneau, H. Chester-Jones, R. C. Chebel, and M. I. Endres. 2015. Cow- and herd-level risk factors for on-farm mortality in Midwest US dairy herds. J. Dairy Sci. 98:4401-4413. https://doi.org/10.3168/jds.2014-8513.

Smith, J. W., L. O. Ely, and A. M. Chapa. 2000. Effect of region, herd size, and milk production on reasons cows leave the herd. J. Dairy Sci. 83:2980-2987. https://doi.org/10.3168/jds.S0022 $-0302(00) 75198-8$

Song, Y., N. Li, J. Gu, S. Fu, Z. Peng, C. Zhao, Y. Zhang, X. Li, Z. Wang, X. Li, and G. Liu. 2016. $\beta$-Hydroxybutyrate induces bovine hepatocyte apoptosis via an ROS-p38 signaling pathway. J. Dairy Sci. 99:9184-9198. https://doi.org/10.3168/jds.2016-11219.

Stokol, T., and D. V. Nydam. 2006. Effect of hemolysis on nonesterified fatty acid and $\beta$-hydroxybutyrate concentrations in bovine blood. J. Vet. Diagn. Invest. 18:466-469. https://doi.org/10.1177/ 104063870601800507.

Suthar, V. S., J. Canelas-Raposo, A. Deniz, and W. Heuwieser. 2013. Prevalence of subclinical ketosis and relationships with postpartum diseases in European dairy cows. J. Dairy Sci. 96:2925-2938. https://doi.org/10.3168/jds.2012-6035.

van der Drift, S. G. A., R. Jorritsma, J. T. Schonewille, H. M. Knijn, and J. A. Stegeman. 2012. Routine detection of hyperketonemia in dairy cows using Fourier transform infrared spectroscopy analysis of $\beta$-hydroxybutyrate and acetone in milk in combination with test-day information. J. Dairy Sci. 95:4886-4898. https://doi.org/ 10.3168/jds.2011-4417.

Vanholder, T., J. Papen, R. Bemers, G. Vertenten, and A. C. B. Berge. 2015. Risk factors for subclinical and clinical ketosis and association with production parameters in dairy cows in the Netherlands. J. Dairy Sci. 98:880-888. https://doi.org/10.3168/jds.2014-8362.

Walsh, R. B., J. S. Walton, D. F. Kelton, S. J. LeBlanc, K. E. Leslie, and T. F. Duffield. 2007. The effect of subclinical ketosis in early lactation on reproductive performance of postpartum dairy cows J. Dairy Sci. 90:2788-2796. https://doi.org/10.3168/jds.2006-560.

Xu, C., T. Shen, Y. Yuan, H. Yu, X. Cheng, and H. Zhang. 2015. Blood clinicopathological differences between type I and II ketosis in dairy cows. Indian J. Anim. Res. 50:753-758. https://doi.org/ 10.18805/ijar.7495.

Youssef, M., and M. El-Ashker. 2017. Significance of insulin resistance and oxidative stress in dairy cattle with subclinical ketosis during the transition period. Trop. Anim. Health Prod. 49:239-244. https: //doi.org/10.1007/s11250-016-1211-6.

\section{ORCIDS}

Z. Rodriguez $\odot$ https://orcid.org/0000-0002-7158-7350

E. Shepley ๑ https://orcid.org/0000-0002-9663-7385

M. I. Endres (ํ) https://orcid.org/0000-0002-1798-3432

G. Cramer (ㄴ) https://orcid.org/0000-0003-2691-3417

L. S. Caixeta @ https://orcid.org/0000-0001-9577-4989 